\title{
The usefulness of arbekacin compared to vancomycin
}

\author{
J.-H. Hwang • J.-H. Lee • M.-K. Moon • J.-S. Kim • \\ K.-S. Won • C.-S. Lee
}

Received: 17 September 2011 / Accepted: 5 November 2011 /Published online: 29 November 2011

(C) The Author(s) 2011. This article is published with open access at Springerlink.com

\begin{abstract}
The bacteriological efficacy response (improved, arbekacin vs. vancomycin; $71.2 \%$ vs. $79.5 \%$ ) and clinical efficacy response (improved, arbekacin vs. vancomycin; $65.3 \%$ vs. $76.1 \%$ ) were not statistically different between the two groups. The complication rate was significantly higher in the vancomycin group (32.9\%) compared to the arbekacin group $(15.1 \%)(p=0.019)$. Arbekacin was not inferior to vancomycin, and it could be a good alternative drug for vancomycin in methicillin-resistant Staphylococcus aureus (MRSA) treatment.
\end{abstract}

\section{Introduction}

Methicillin-resistant Staphylococcus aureus (MRSA) is frequently resistant to the majority of commonly used

J.-H. Hwang and J.-H. Lee contributed equally to this work.

J.-H. Hwang • M.-K. Moon · J.-S. Kim • K.-S. Won

The Department of Pharmacy,

Chonbuk National University Hospital,

Jeonju, Jeonbuk, South Korea

\section{J.-H. Lee}

The Department of Preventive Medicine, Chonbuk National University Medical School, Jeonju, Jeonbuk, South Korea

\section{C.-S. Lee $(\square)$}

The Department of Internal Medicine, Chonbuk National University Medical School,

San 2-20, Geumam-Dong, Deokjin-Gu,

Jeonju, Jeonbuk, South Korea

e-mail: 1csmd@jbnu.ac.kr

J.-H. Lee $\cdot$ C.-S. Lee

Research Institute of Clinical Medicine,

Jeonju, Republic of Korea antimicrobial agents, including beta-lactam antibiotics, aminoglycosides, macrolides, chloramphenicol, tetracycline, and fluoroquinolones [1]. The prevalence of methicillin resistance is known to be more than $\sim 60-70 \%$ among $S$. aureus isolates from hospitals in Korea [2, 3]. MRSA has become a one of the most important causes of nosocomial pathogenic infections, and the use of vancomycin for the treatment of MRSA infection has increased [4]. Unfortunately, vancomycin-resistant Enterococcus (VRE) and vancomycinresistant coagulase-negative Staphylococcus (VRCNS) have been reported, as well as vancomycin-resistant $S$. aureus (VRSA) [5-7]. To prevent the spread of VRE, VRCNS, and VRSA, the use of vancomycin has to be reduced. This will require the introduction of a new class of antibiotics that can replace vancomycin [8].

Arbekacin is an antibacterial agent and belongs to the aminoglycoside family of antibiotics. It was introduced to treat MRSA infection. Pharmacokinetic advantages such as concentration-dependant bactericidal activity and prolonged post-antibiotic effect are more appreciable than vancomycin [9]. However, only a few reports of clinical data describing this new kind of antibiotic exist outside of Japan, which was the first country that approved its use against MRSA infections [10]. Therefore, presently, MRSA infection is treated mainly with vancomycin and teicoplanin, which are glycopeptide antibiotics.

We studied the clinical and bacteriological efficacy and safety of arbekacin compared to vancomycin in the treatment of infections caused by MRSA.

\section{Method}

This was a retrospective case-control study of patients who were admitted to Chonbuk National University Hospital, a 
Table 1 General characteristics of the study population

\begin{tabular}{|c|c|c|c|}
\hline & Arbekacin $(n=73)$ & Vancomycin $(n=73)$ & $p$-value \\
\hline Age (years) & $54.1 \pm 16.4$ & $56.3 \pm 14.7$ & 0.397 \\
\hline \multicolumn{4}{|l|}{ Sex } \\
\hline Male & $43(58.9 \%)$ & $43(58.9 \%)$ & \multirow[t]{2}{*}{1.000} \\
\hline Female & $30(41.1 \%)$ & $30(41.1 \%)$ & \\
\hline \multicolumn{4}{|l|}{ Department } \\
\hline Medical & $15(20.5 \%)$ & $38(52.1 \%)$ & \multirow[t]{2}{*}{$<0.001$} \\
\hline Surgical & $58(79.5 \%)$ & $35(47.9 \%)$ & \\
\hline \multicolumn{4}{|l|}{ Clinical status } \\
\hline Sepsis & $5(6.8 \%)$ & $6(8.2 \%)$ & \multirow[t]{3}{*}{0.063} \\
\hline Wound- and catheter-related & $45(61.6 \%)$ & $31(42.5 \%)$ & \\
\hline Others $^{\mathrm{a}}$ & $23(31.5 \%)$ & $36(49.3 \%)$ & \\
\hline Medication duration (days) & $19.4 \pm 15.7$ & $18.2 \pm 11.3$ & 0.608 \\
\hline
\end{tabular}

1,100-bed tertiary care university hospital in Jeonju, Korea, from January 1st, 2009 to May 31st, 2010, and received the antibiotics arbekacin or vancomycin. All of the MRSAinfected patients who received arbekacin were enrolled during the study period. The vancomycin group infected by MRSA was selected by age and sex that matched the arbekacin group. The study protocol was approved by the Institutional Review Board of Chonbuk National University Hospital.

In this study, nephrotoxicity was defined as when at least $50 \%$ reduction was seen in the glomerular filtration rate (GFR) using the abbreviated modified diet in the renal disease (MDRD) equation, which was GFR $\left(\mathrm{mL} / \mathrm{min} / 1.73 \mathrm{~m}^{2}\right)=186$ $\mathrm{P}_{\mathrm{cr}}{ }^{-1.154} \times$ age $^{-0.203} \times(1.212$ if black $) \times(0.742$ if female $)$ [11]. Hepatotoxicity was defined as when the aspartate aminotransferase/alanine aminotransferase (ALT/AST) levels were raised over two times the baseline values during treatment. Leukocytopenia was defined as a continuous decrease lower than $4.8 \times 10^{3} / \mu \mathrm{L}$ in the number of white blood cells found in the complete blood cell count during treatment. Drug fever was defined as a disorder characterized by fever coinciding with the administration of a drug and disappearing after the discontinuation of the drug [12].

The bacteriological efficacy response (BER) was classified with improved and failure. The improved BER was defined as no growth of MRSA, whereas failure was defined as the growth of MRSA culture at the end of therapy or during treatment. The clinical efficacy response (CER) was classified as improved and failure. Improved CER was defined as resolution or reduction of the majority of signs and symptoms related to the original infection. Failure was defined as no resolution and no reduction of the majority of the signs and symptoms, or the worsening of one or more signs and symptoms, or new symptoms or signs associated with the original infection or a new infection [13].

Categorical variables were compared by the Chi-squared test and continuous variables were compared by the unpaired $t$-test. SPSS software (version 15.0) was used throughout and $p$-values of less than 0.05 were considered to be statistically significant.
Table 2 Safety and outcomes in patients receiving arbekacin or vancomycin
N/A, not applicable; BER, bacteriological efficacy response; CER, clinical efficacy response

Analyzed by the Chi-squared test

\begin{tabular}{|c|c|c|c|c|}
\hline & & Arbekacin $(n=73)$ & Vancomycin $(n=73)$ & $p$-value \\
\hline \multicolumn{5}{|c|}{ Complications } \\
\hline \multirow{7}{*}{$\begin{array}{l}\text { No } \\
\text { Yes }\end{array}$} & & $62(84.9 \%)$ & $49(67.1 \%)$ & \multirow[t]{2}{*}{0.019} \\
\hline & & $11(15.1 \%)$ & $24(32.9 \%)$ & \\
\hline & Nephrotoxicity & $5(6.8 \%)$ & $6(8.2 \%)$ & 0.754 \\
\hline & Leukopenia & $4(5.5 \%)$ & $5(6.8 \%)$ & 0.731 \\
\hline & Hepatotoxicity & $3(4.1 \%)$ & $3(4.1 \%)$ & 1.000 \\
\hline & Skin rash & $0(0.0 \%)$ & $5(6.8 \%)$ & N/A \\
\hline & Drug fever & $0(0.0 \%)$ & $6(8.2 \%)$ & N/A \\
\hline \multicolumn{5}{|c|}{ Outcomes } \\
\hline \multirow[t]{2}{*}{ BER } & Improved & $52(71.2 \%)$ & $58(79.5 \%)$ & \multirow[t]{2}{*}{0.249} \\
\hline & Failure & $21(28.8 \%)$ & $15(20.5 \%)$ & \\
\hline \multirow[t]{2}{*}{ CER } & Improved & $47(65.3 \%)$ & $54(76.1 \%)$ & \multirow[t]{2}{*}{0.157} \\
\hline & Failure & $25(34.7 \%)$ & $17(23.9 \%)$ & \\
\hline
\end{tabular}




\section{Results}

A total of 146 patients were enrolled in this study. Seventythree patients receiving arbekacin were compared with the same number of patients receiving vancomycin (Table 1). The mean age of the arbekacin group was $54.1 \pm 16.4$ years, and that of the vancomycin group was 56.3 \pm 14.7 years. There was no gender difference between the two groups. The arbekacin group was more common in surgical section than the vancomycin group $(p<0.001)$. The clinical status $(p=0.063)$ or the medication duration $(19.4 \pm 15.7$ days vs. $18.2 \pm 11.3$ days) was not different between the two groups.

The complications of the antibiotics between the two groups were different (Table 2). The complication rate was significantly higher in the vancomycin group (32.9\%) than in the arbekacin group $(15.1 \%)(p=0.019)$. However, individual complications such as nephrotoxicity, leukopenia, and hepatotoxicity were not significantly different between the two groups. Skin rash and drug fever occurred only among patients in the vancomycin group. In the outcome section, the BER (improved, arbekacin vs. vancomycin; 71.2\% vs. $79.5 \%$ ) and the CER (improved, arbekacin vs. vancomycin; $65.3 \%$ vs. $76.1 \%$ ) were not statistically different between the two groups (Table 2).

\section{Discussion}

In this study, arbekacin had a similar efficacy to vancomycin in patients with MRSA. In addition, the side effects in the arbekacin group were significantly lower than in the vancomycin group. This showed that arbekacin may be a good alternative drug for the treatment of infectious disease with MRSA. Furthermore, this could lead to the decrease of vancomycin usage in hospitals and decrease antibioticresistant microorganisms, particularly VRE and vancomycinintermediate $S$. aureus (VISA), in clinical settings.

Approximately $80 \%$ of $S$. aureus strains isolated in intensive care units (ICUs) are resistant to methicillin in Asia [14]. More than $60 \%$ of MRSA were found in central line-associated bloodstream infections in ICUs from the United States [15]. Glycopeptides such as vancomycin and teicoplanin are still the most frequently chosen antibiotics for the treatment of MRSA infections, but the susceptibility to vancomycin diminished in MRSA strains [16]. In addition, VRSA strains have emerged in clinical settings [17]. Although VRSA infections continue to be rare and no transmission has been identified, it remains a serious public health concern all over the world. It was shown that, with more vancomycin exposure, there was a higher risk for VRSA or VRE [17]. Prudent use of vancomycin as well as the development of alternative therapeutic options against MRSA is, therefore, required.
Arbekacin, a derivative of the aminoglycoside dibekacin, has been reported to have good in vitro activity against MRSA [18, 19]. Previous reports showed that the majority of MRSA isolates in Europe and Japan were susceptible to arbekacin [20]. Arbekacin has been used for the treatment of MRSA infections is shown to be as useful as vancomycin based on clinical data $[21,22]$. Lee et al. showed that arbekacin-based combination regimens could be an alternative option for glycopeptides in the treatment of MRSA or heteroVISA infection [19]. In this study, arbekacin was not different to vancomycin in clinical trials. This shows that arbekacin could be a good alternative drug for glycopeptides.

The major side effects of vancomycin include local phlebitis, fever, neutropenia, skin rash, and renal toxicity [23]. The major side effects of arbekacin were renal and ear toxicity, like other aminoglycosides [18]. In this study, individual side effects of the antibiotics were not different between the two groups. However, arbekacin had fewer side effects than vancomycin overall.

There were several limitations in this study. First, it was a retrospective case-control study. Second, the two groups were not balanced at the clinical department. Surgical patients had a higher representation in the arbekacin group. However, the clinical status was not different between the two groups.

In conclusion, arbekacin was not inferior to vancomycin. We suggest that arbekacin could be a good alternative drug for vancomycin in MRSA treatment in the hospital. More well-designed studies are required in order to evaluate the exact clinical response between arbekacin and vancomycin.

Open Access This article is distributed under the terms of the Creative Commons Attribution Noncommercial License which permits any noncommercial use, distribution, and reproduction in any medium, provided the original author(s) and source are credited.

\section{References}

1. Ma XX, Ito T, Tiensasitorn C, Jamklang M, Chongtrakool P, Boyle-Vavra S, Daum RS, Hiramatsu K (2002) Novel type of staphylococcal cassette chromosome mec identified in communityacquired methicillin-resistant Staphylococcus aureus strains. Antimicrob Agents Chemother 46(4):1147-1152

2. Chung GT, Cha JG, Han SY, Jang HS, Lee KM, Yoo JI, Yoo JS, Kim HB, Eun SH, Kim BS, Park O, Lee YS (2010) Nationwide surveillance study of vancomycin intermediate Staphylococcus aureus strains in Korean Hospitals from 2001 to 2006. J Microbiol Biotechnol 20(3):637-642

3. Lee KW, Lee MA, Lee CH, Lee JW, Roh KH, Kim SJ, Kim JJ, Koh EM, Yong DE, Chong YS, KONSAR Group (2010) Increase of ceftazidime- and fluoroquinolone-resistant Klebsiella pneumoniae and imipenem-resistant Acinetobacter spp. in Korea: analysis of KONSAR study data from 2005 and 2007. Yonsei Med J 51(6):901-911

4. Kim JM, Park ES, Jeong JS, Kim KM, Kim JM, Oh HS, Yoon SW, Chang HS, Chang KH, Lee SI, Lee MS, Song JH, Kang MW, 
Park SC, Choe KW, Pai CH (2000) Multicenter surveillance study for nosocomial infections in major hospitals in Korea. Nosocomial Infection Surveillance Committee of the Korean Society for Nosocomial Infection Control. Am J Infect Control 28(6):454-458

5. Hiramatsu K, Hanaki H, Ino T, Yabuta K, Oguri T, Tenover FC (1997) Methicillin-resistant Staphylococcus aureus clinical strain with reduced vancomycin susceptibility. J Antimicrob Chemother 40(1):135-136

6. Smith TL, Pearson ML, Wilcox KR, Cruz C, Lancaster MV, Robinson-Dunn B, Tenover FC, Zervos MJ, Band JD, White E, Jarvis WR (1999) Emergence of vancomycin resistance in Staphylococcus aureus. Glycopeptide-Intermediate Staphylococcus aureus Working Group. N Engl J Med 340(7):493-501

7. Centers for Disease Control and Prevention (CDC) (2000) Staphylococcus aureus with reduced susceptibility to vancomycin-Illinois, 1999. MMWR Morb Mortal Wkly Rep 48(51-52):1165-1167

8. Wie SH, Kang JH, Huh DH, Lee DG, Kim SI, Kim YR, Choi JH, Kim JH, Yoo JH, Hur JK, Shin WS, Kang MW (2001) Antimicrobial activities of arbekacin against clinical isolates of Staphylococcus aureus and coagulase-negative Staphylococcus species. Korean J Infect Dis 33(4):254-260

9. Watanabe T, Ohashi K, Matsui K, Kubota T (1997) Comparative studies of the bactericidal, morphological and post-antibiotic effects of arbekacin and vancomycin against methicillin-resistant Staphylococcus aureus. J Antimicrob Chemother 39(4):471-476

10. Kim TH, Choo EJ, Lee MS, Kim NJ, Woo JH, Ryu J, Chang MS, Yum YK (2003) Clinical efficacy and safety with arbekacin for methicillin-resistant Staphylococcus aureus (MRSA) infections. Korean J Med 65(2):239-244

11. Manjunath G, Sarnak MJ, Levey AS (2001) Prediction equations to estimate glomerular filtration rate: an update. Curr Opin Nephrol Hypertens 10(6):785-792

12. Mackowiak PA, LeMaistre CF (1987) Drug fever: a critical appraisal of conventional concepts. An analysis of 51 episodes in two Dallas hospitals and 97 episodes reported in the English literature. Ann Intern Med 106(5):728-733

13. Choo EJ, Choi SH, Cho YW, Chung SM, Kim BN, Kim NJ et al (2002) Clinical experience with quinupristin-dalfopristin treatment for vancomycin-resistant enterococcal infection. J Korean Soc Chemother 20(1):17-24
14. Rosenthal VD, Maki DG, Mehta A, Alvarez-Moreno C, Leblebicioglu $\mathrm{H}$, Higuera F, Cuellar LE, Madani N, Mitrev Z, Dueñas L, Navoa-Ng JA, Garcell HG, Raka L, Hidalgo RF, Medeiros EA, Kanj SS, Abubakar S, Nercelles P, Pratesi RD, International Nosocomial Infection Control Consortium Members (2008) International Nosocomial Infection Control Consortium report, data summary for 20022007, issued January 2008. Am J Infect Control 36(9):627-637

15. Burton DC, Edwards JR, Horan TC, Jernigan JA, Fridkin SK (2009) Methicillin-resistant Staphylococcus aureus central lineassociated bloodstream infections in US intensive care units, 1997-2007. JAMA 301(7):727-736

16. Wang G, Hindler JF, Ward KW, Bruckner DA (2006) Increased vancomycin MICs for Staphylococcus aureus clinical isolates from a university hospital during a 5-year period. J Clin Microbiol 44(11):3883-3886

17. Sievert DM, Rudrik JT, Patel JB, McDonald LC, Wilkins MJ, Hageman JC (2008) Vancomycin-resistant Staphylococcus aureus in the United States, 2002-2006. Clin Infect Dis 46(5):668-674

18. Sato R, Tanigawara Y, Kaku M, Aikawa N, Shimizu K (2006) Pharmacokinetic-pharmacodynamic relationship of arbekacin for treatment of patients infected with methicillin-resistant Staphylococcus aureus. Antimicrob Agents Chemother 50 (11):3763-3769

19. Lee DG, Chun HS, Yim DS, Choi SM, Choi JH, Yoo JH, Shin WS, Kang MW (2003) Efficacies of vancomycin, arbekacin, and gentamicin alone or in combination against methicillin-resistant Staphylococcus aureus in an in vitro infective endocarditis model. Antimicrob Agents Chemother 47(12):3768-3773

20. Hamilton-Miller JM, Shah S (1995) Activity of the semi-synthetic kanamycin B derivative, arbekacin against methicillin-resistant Staphylococcus aureus. J Antimicrob Chemother 35(6):865-868

21. Suzuki K (2003) Efficacy and safety of arbekacin for staphylococcal infection in the NICU. Pediatr Int 45(3):301-306

22. Kobayashi Y, Uchida H, Kawakami Y (1995) Arbekacin. Int J Antimicrob Agents 5(4):227-230

23. Lodise TP, Patel N, Lomaestro BM, Rodvold KA, Drusano GL (2009) Relationship between initial vancomycin concentrationtime profile and nephrotoxicity among hospitalized patients. Clin Infect Dis 49(4):507-514 